\title{
Evaluation of high performance Ge-MOS structure using high dielectric constant material
}

\author{
[oTakeshi Tokorozuki, Yoshitaka Iwazaki, Tomo Ueno]
}

\begin{abstract}
Currently, as next - generation MOS devices, a highk/Ge structure, which has high electron and hole mobility than that of $\mathrm{Si}$, and has the ability to low power consumption during device operation has been expected. Although $\mathrm{HfO}_{2}$ which exhibits excellent characteristics on silicon can be applied as high-k material, it is known that $\mathrm{Ge}$ and $\mathrm{HfO}_{2}$ cause diffusion of atoms due to heat treatment during device fabrication process and deteriorate electric characteristics such as large leakage current in $\mathrm{HfO}_{2}$ film and large interface trap density at the $\mathrm{HfO}_{2} / \mathrm{Ge}$ interface. Therefore, lower fabrication process temperature has been attempted by introducing $\mathrm{Kr} / \mathrm{O}_{2}$ plasma oxidation instead of conventional thermal oxidation method in this research. As a result, compared to thermal oxidation, the leakage current is greatly reduced and the electrical characteristics are drastically improved by using $\mathrm{Kr} / \mathrm{O}_{2}$ plasma oxidation. Therefore, we can conclude that high quality $\mathrm{HfO}_{2}$ can be formed on Ge substrates, and that interface defects and traps in the film have been successfully suppressed using $\mathrm{Kr} / \mathrm{O}_{2}$ plasma oxidation method.
\end{abstract}

Keywords - Ge, $\mathrm{HfO}_{2}$, MOSFET, $\mathrm{Kr} / \mathrm{O}_{2}$ plasma

\section{Introduction}

\section{A. The structure of MOSFET}

There are many devices using semiconductors, in particular, MOSFETs made of M(metal)-O(oxide)-S(semiconductor) are very important switching elements mainly used in LSIs. When no voltage is applied to the gate, no current flows between the drain and the source. However, when a positive voltage is applied to the gate metal, electrons are accumulated just under the insulating film and the surface of p-type semiconductor layer tend to be inverted, so that the carriers at source region can move to drain region. MOSFETs make it possible to perform ON / OFF switching of current using this characteristic. Currently, widely used Si - MOSFETs have

\footnotetext{
- O Takeshi Tokorozuki, Yoshitaka Iwazaki, Tomo Ueno. Tokyo univ. of agri. and tech.

Japan
}

been improved in performance with miniaturization, but there is also a problem that carrier mobility is low, and research on high performance MOSFETs using new materials has been advanced recently.

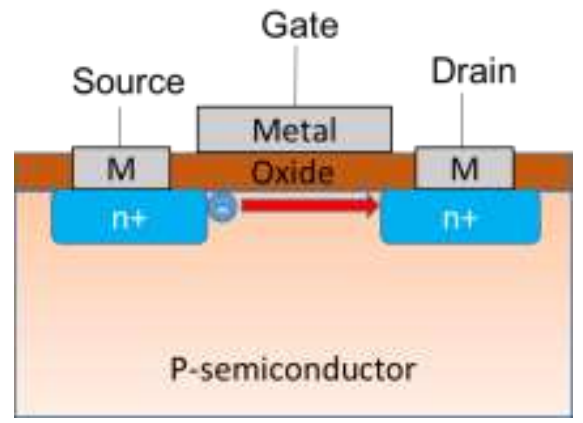

Fig.1 Structure of MOSFET

\section{B. Issues to be addressed}

We have focused on Ge as a new material instead of Si. The use of $\mathrm{Ge}$ is expected to be able to improve the switching speed of MOSFET due to its high hole and electron mobility [3]. In addition, $\mathrm{HfO}_{2}$ of a high dielectric constant material was introduced into the insulating film. It is expected that this material has a dielectric constant of approximately 7 times higher than that of conventionally used $\mathrm{SiO}_{2}$, and carriers can be accumulated even at low gate voltage. However, it is reported that component atoms of $\mathrm{Ge}$ and $\mathrm{HfO}_{2}$ diffuse at the interface due to heat treatment during device fabrication process, and electric characteristics are shown to be very poor [1] [2] [4]. Therefore, the $\mathrm{Kr} / \mathrm{O}_{2}$ plasma oxidation method has been carried out instead of the thermal oxidation method conventionally used for the oxidation of $\mathrm{Hf}$. In this $\mathrm{Kr} / \mathrm{O}_{2}$ plasma oxidation method, low temperature oxidation can be expected due to the strong oxidation power of atomic oxygen generated in the plasma (the mechanism is shown in Fig.2). In this study, we have examined whether this oxidation method is effective for fabrication of $\mathrm{HfO}_{2} / \mathrm{Ge}$ structure, and attempted to improve electric characteristics by lowering the manufacturing process.

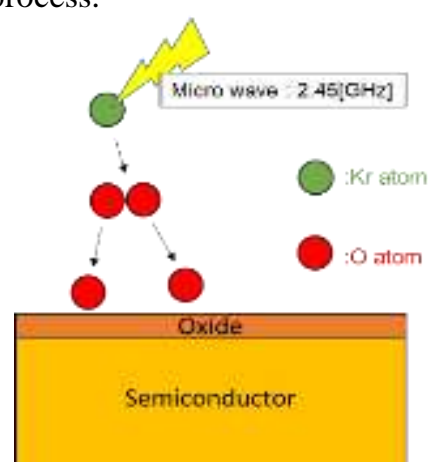

Fig.2 Mechanism of $\mathrm{Kr} / \mathrm{O}_{2}$ plasma oxidation 


\section{Device fabrication}

P-type Ge (100) substrate with a resistivity $\sim 0.5[\Omega \cdot \mathrm{cm}]$ was used as the substrates. After conventional chemical cleaning, the native oxide film on the Ge wafer was removed in dilute $\mathrm{HF}$ for 10 [min] and immediately placed in a sputtering apparatus, and $5[\mathrm{~nm}]$-thick $\mathrm{Hf}$ was deposited on the $\mathrm{Ge}$ substrate. Then, $\mathrm{Kr} / \mathrm{O}_{2}$ plasma oxidation with a temperature range of $350\left[{ }^{\circ} \mathrm{C}\right], 300\left[{ }^{\circ} \mathrm{C}\right], 250\left[{ }^{\circ} \mathrm{C}\right]$ and 200 $\left[{ }^{\circ} \mathrm{C}\right]$ in 60 [min] was carried out. For comparison, thermal oxidation was also carried out in the oxidation furnace at 350 $\left[{ }^{\circ} \mathrm{C}\right]$ for 60 [min]. Finally, an $\mathrm{Al}$ electrode was evaporated to fabricate the $\mathrm{Al} / \mathrm{HfO}_{2} / \mathrm{Ge}$ structure for each electrical measurement. C-V (capacitance versus voltage) and $\mathrm{J}-\mathrm{V}$ (current density versus voltage) measurements were carried out at R.T. The measurement frequency of $\mathrm{C}-\mathrm{V}$ is in the range of $10[\mathrm{kHz}]$ to 1 [MHz].

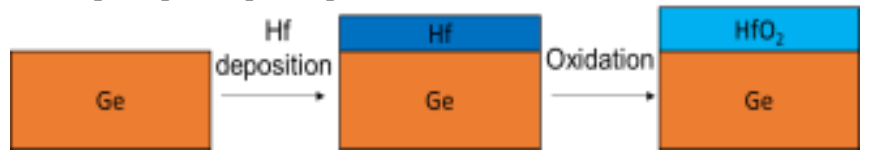

Fig.3 Sample fabrication flowchart

\section{Result and Discussion}

\section{A. Thermal oxidation and $\mathrm{Kr} / \mathrm{O}_{2}$ plasma oxidation}

A Fig. 4 shows $\mathrm{C}-\mathrm{V}$ and $\mathrm{J}-\mathrm{V}$ characteristics of $\mathrm{HfO}_{2} / \mathrm{Ge}$ structures as a function of oxidation method such as $\mathrm{Kr} / \mathrm{O}_{2}$ plasma oxidation and thermal oxidation, respectively. In the case of thermal oxidation, the shape of $\mathrm{C}-\mathrm{V}$ curve is shown to be strange, whereas plasma oxidation shows almost ideal shape of $\mathrm{C}-\mathrm{V}$ characteristics of MOS structure. In addition, plasma oxidation from the $\mathrm{J}-\mathrm{V}$ characteristics shows that the leakage current is much smaller, so it is considered that $\mathrm{HfO}_{2}$ with lower defect density could be formed even at low temperature of $350\left[{ }^{\circ} \mathrm{C}\right]$ compared to thermal oxidation. From these results, it was found that the $\mathrm{Kr} / \mathrm{O}_{2}$ plasma oxidation method is effective for the oxidation of $\mathrm{Hf}$ at low temperature.
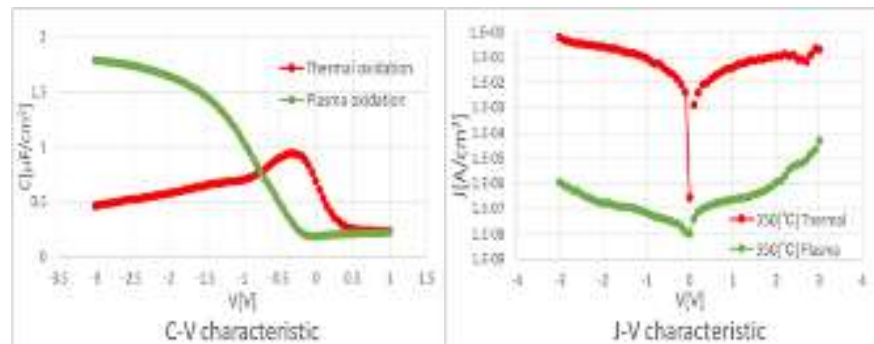

Fig.4 $350\left[{ }^{\circ} \mathrm{C}\right] \mathrm{Kr} / \mathrm{O}_{2}$ plasma oxidation and thermal oxidation $\mathrm{C}-\mathrm{V}, \mathrm{J}-\mathrm{V}$ characteristics

\section{B. Low temperature $\mathrm{Kr} / \mathrm{O}_{2}$ plasma oxidation}

In this section, dependence of $\mathrm{C}-\mathrm{V}$ characteristics on oxidation temperature is shown. Fig.5 shows $\mathrm{C}-\mathrm{V}$ characteristics for each oxidation temperature.

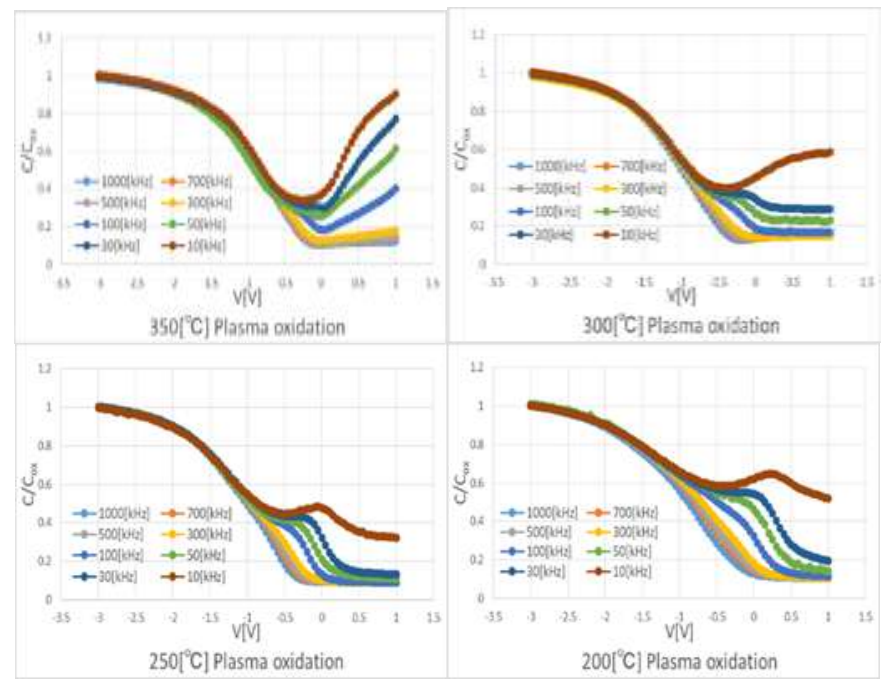

Fig.5 C-V characteristic for each oxidation temperature

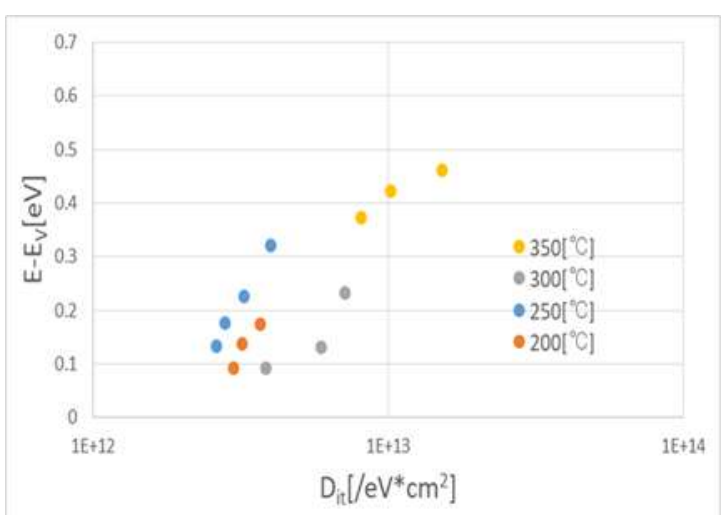

Fig.6 $D_{\text {it }}$ for each oxidation temperature using $\mathrm{Kr} / \mathrm{O}_{2}$ using plasma oxidation

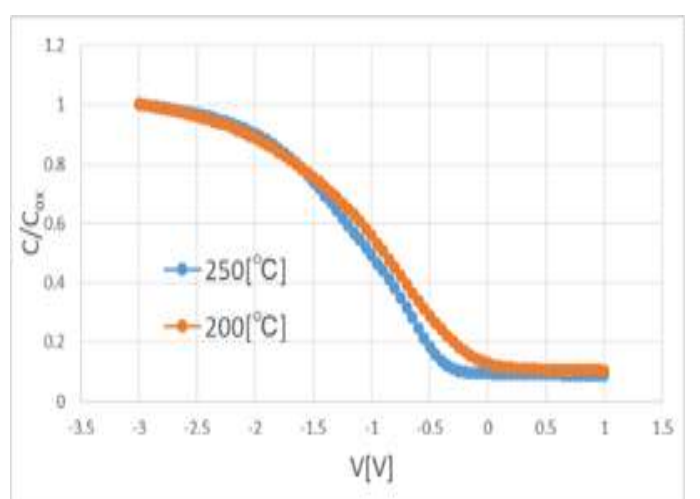

Fig.7 Comparison of high frequency C-V characteristics $200\left[{ }^{\circ} \mathrm{C}\right]$ and $250\left[{ }^{\circ} \mathrm{C}\right]$

As is shown in Fig. 5, since atomic diffusion occurred at $350\left[{ }^{\circ} \mathrm{C}\right]$, the frequency dispersion due to the interface defects was large in the inversion region of $\mathrm{C}-\mathrm{V}$ characteristics, but as the oxidation temperature was lowered, the dispersion tend to decrease and the interface properties would be improved. However, as shown in Fig.6, $\mathrm{D}_{\text {it }}$ was increased at $200\left[{ }^{\circ} \mathrm{C}\right]$ compared to $250\left[{ }^{\circ} \mathrm{C}\right]$, and the stretch out was also increased, 
Proc. of the Eighth Intl. Conf. on Advances in Computing, Electronics and Communication - ACEC 2019

Copyright ( $)$ Institute of Research Engineers and Doctors. All rights reserved.

ISBN: 978-1-63248-165-8 DOI : 10.15224/978-1-63248-165-8-10
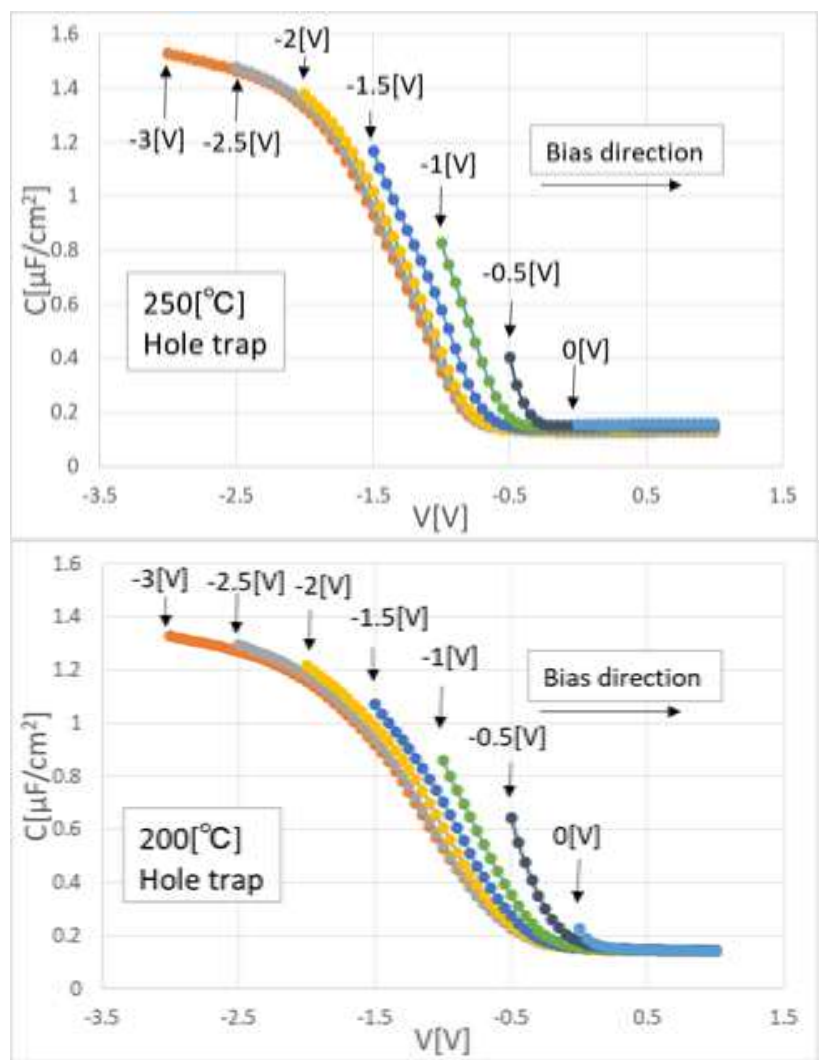

Fig.8 Positive bias C-V sweep at $200\left[{ }^{\circ} \mathrm{C}\right], 250\left[{ }^{\circ} \mathrm{C}\right]$

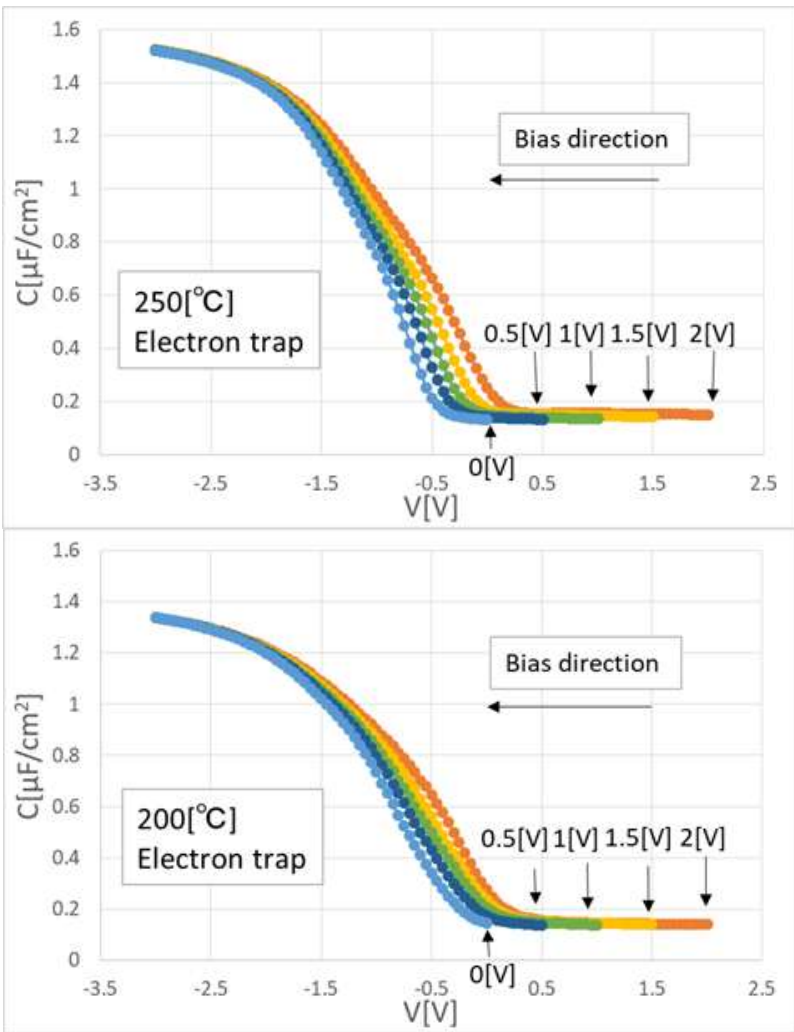

Fig.9 Negative bias C-V sweep at $200\left[{ }^{\circ} \mathrm{C}\right], 250\left[{ }^{\circ} \mathrm{C}\right]$ so interface defects increased. In Figs.8 and 9, the characteristics of defects are shown in detail by changing the start voltage of $\mathrm{C}-\mathrm{V}$ and bias direction at $200\left[{ }^{\circ} \mathrm{C}\right]$ and 250 $\left[{ }^{\circ} \mathrm{C}\right]$. First, as shown in Fig.8, the C-V curve shifted to the left as the measurement start voltage was increased negatively in both cases. This is because holes are injected into the defect from the Ge substrate, and positive charges are apparent. From these results, it was suggested that hole traps exist in both films. In the case of $200\left[{ }^{\circ} \mathrm{C}\right]$, the shift decreases from 250 $\left[{ }^{\circ} \mathrm{C}\right]$ in the range from $-1[\mathrm{~V}]$ to $-2[\mathrm{~V}]$, so it is considered that the hole trap in the film decreased.

Next, from the result of Fig. 9, in both cases, the C-V curve shifts to the right by increasing the starting voltage positively, and in addition, the slope of the $\mathrm{C}-\mathrm{V}$ curve decreases. Although electrons are captured in the film at the start, it is considered that electrons are emitted during the sweep. Generally speaking, fast state trap would be located just at the $\mathrm{HfO}_{2} / \mathrm{Ge}$ interface and this cause frequency dispersion and stretch out whereas slow state trap would be located in the $\mathrm{HfO}_{2}$ layer adjacent to the interface with a few [nm] apart and this cause hysteresis. From the point of view, the $\mathrm{C}-\mathrm{V}$ characteristics shown in Fig.9, represents, the existence of "middle state trap" which is located between slow and fast state traps. Since the shift of $200\left[{ }^{\circ} \mathrm{C}\right]$ is reduced as compared with that of $250\left[{ }^{\circ} \mathrm{C}\right]$, it is suggested that the electron trap also decreases like the hole traps. From these results, the inferred band model is shown in Fig.10.

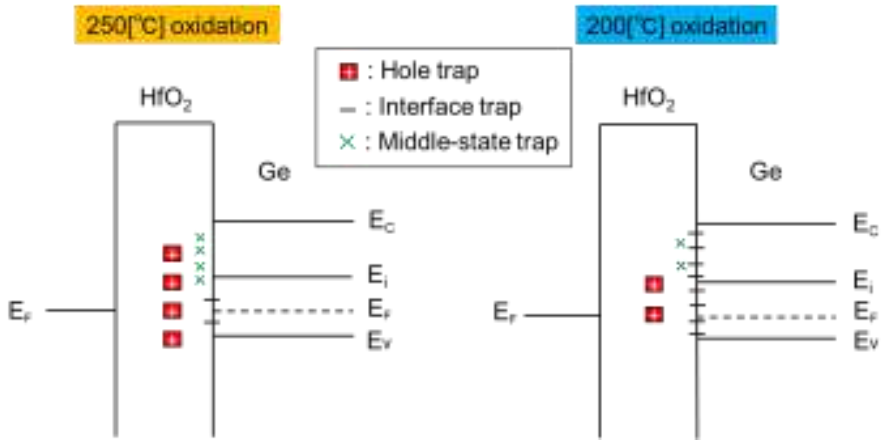

Fig.10 $250\left[{ }^{\circ} \mathrm{C}\right], 200\left[{ }^{\circ} \mathrm{C}\right]$ band model

\section{Conclusion}

We have found that $\mathrm{Kr} / \mathrm{O}_{2}$ plasma oxidation method can produce high-quality $\mathrm{HfO}_{2}$ even at low temperature compared to thermal oxidation method, and by using this method to lower the temperature of the $\mathrm{HfO}_{2} / \mathrm{Ge}$ structure fabrication process dramatically improve interface characteristics. In addition, under these experimental condition, lowest $D_{\text {it }}$ value could be obtained with the processing temperature of $250\left[{ }^{\circ} \mathrm{C}\right]$. When oxidation was performed at a temperature lower than $250\left[{ }^{\circ} \mathrm{C}\right]$ the trap in the film decreased but the interface defect increased.

\section{References}

[1] M.Caymax, S.Van Elshocht, M.Houssa, A.Delabie, T.Conard, M.Meuris, M.M.Heyns, A.Dimoulas, S.Spiga, M.Fancil, J.W.Seo, L.V.Goncharova, " $\mathrm{HfO}_{2}$ as gate dielectric on Ge: Interfaces and 
Proc. of the Eighth Intl. Conf. on Advances in Computing, Electronics and Communication - ACEC 2019

Copyright (C) Institute of Research Engineers and Doctors. All rights reserved.

ISBN: 978-1-63248-165-8 DOI : 10.15224/978-1-63248-165-8-10

deposition tecniques," Materials Science and Engineering: B, Vol. 135, Issue 3, pp. 256-260, 2006.

[2] Shiyang ZHU and Anri Nakajima, "Atomic Layer Deposition of $\mathrm{HfO}_{2}$ and $\mathrm{Si}$ Nitridation on Ge Substrates," Japanese Journal Physics, Vol.46, No. 12, pp. 7699-7701, 2007.

[3] Yusuke Oniki, Hideo Koumo, Yositaka Iwazaki, Tomo Ueno, "Evaluation of $\mathrm{GeO}$ desorption behavior in the metal $/ \mathrm{GeO}_{2} / \mathrm{Ge}$ structure and its improvement of the electrical characteristics," Journal of Applied Physics, Vol. 107, Issue 12, 2010.

[4] Yoshiki Kamata, Yuuichi Kamimuta, Tsunehiro Ino, Akira Nishiyama, "Direct Comparison Of ZrO2 and HfO2 on Ge Substrate in Terms of the Realization of Ultrathin High-k Gate Stacks," Japanese journal of Applied Physics, Vol.44, No.4B, pp. 2323-2329, 2005.

About Author (s):

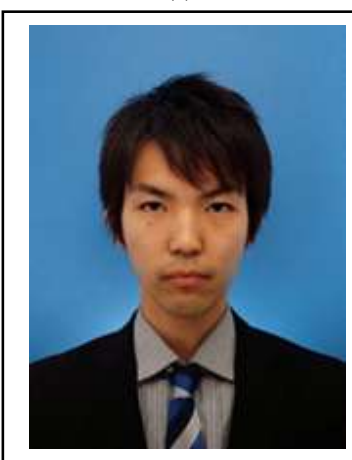

Takeshi Tokorozuki

Master Course, Department of Electrical and Electronic Engineering, graduate school of TUAT (Tokyo univ. of agri. and tech, Japan) 